\title{
Design and development of FRP mobile fish vending trolley for hygienic fish marketing
}

\author{
B. C. Mohapatra*, P. Sahoo, D. Majhi, K. Anantharaja and P. Jayasankar \\ ICAR-Central Institute of Freshwater Aquaculture, Kausalyaganga, Bhubaneswar-751002 (Odisha), INDIA \\ *Corresponding author. E-mail: bcmohapatra65@gmail.com
}

Received: March 12, 2016; Revised received: October 1, 2016; Accepted: January 3, 2017

\begin{abstract}
A mobile fish vending trolley has been designed and developed by Indian Council of Agricultural Research (ICAR) - All India Coordinated Research Project on Plasticulture Engineering and Technology (AICRP on PET) centre at ICAR-Central Institute of Freshwater Aquaculture (ICAR-CIFA), Bhubaneswar to aid the fisher folks for vending their fish harvests in hygienic condition. The unique selling proposition (USP) of the vending unit is its unibody design, where icebox for storing fish, 20 I capacity water storage tank for hand washing, tool box, fish cutting deck and waste collection chambers are integrated into the unit. The icebox can store $100 \mathrm{~kg}$ of fish in ice which can be sold in a single day by the fisher folks. The complete unit of mobile fish vending carriage is fabricated with fibre reinforced plastic (FRP), because of its high strength compared to other plastics, ease of fabrication and good insulation property of fiberglass (i.e. thermal conductivity $=0.04 \mathrm{w} / \mathrm{mK}$ at normal room temperature $25^{\circ} \mathrm{C}$ ). The dimensions of the carriage unit is 4.0'x2'9"x2'6" in which half portion is dedicated for the insulated ice box and the remaining portion houses the fish cutting deck, waste collection chamber and tool box. This fish vending trolley would be a boon for the marginal fish vendors, who want to sell fish in a hygienic condition and to increase income generation potential by selling $100 \mathrm{~kg}$ fish in a day.
\end{abstract}

Keywords: Fish vendor, FRP, Hygienic fish marketing, Mobile fish vending trolley

\section{INTRODUCTION}

Fish farming has garnered huge acceptability in the farming community because of high rates of return compared to other agricultural farming entities. With the advancement of new techniques and processes of fish farming, production capacity has also increased as a whole. But marketing of the fish harvests has proved to be a bottleneck for the farmers. No matter how much more production has increased, but the fish vendors are finding it increasingly difficult to sell the harvested fish in hygienic condition in the market due to unavailability of proper and economic fish vending carriages and structures (Sharma, 2010).

Fish vendors can be broadly classified as Stationary vendors who vend on a regular basis at specific locations, Peripatetic vendors who walk from place to place to sell their fish and Mobile vendors who move around on bicycles or motorized vehicles. Mobile fish vending is very common in states such as Odisha in which the vendors arrive at the landing centres from different villages and purchase fish at auctions at the village/ wholesale markets/ landing centres, for sale back in their villages. They also sell fish door-to-door (Sharma, 2010). Also, maintaining hygiene is also a key element in the fish vending process. The current scenario of fish marketing sector has been worsened due to the unhygienic fish vending practices of the vendors that relates to sanitation, fish handling and artisanal fish processing (Kyangwa and Odongkara, 2005). Normally the vendors carry the fish in ice in a basket, made of bamboo or plastic, fitted on a bicycle carrier and travel to smaller distances for sale. This has also restricted them from selling large quantities of fish in the market in a single day and there by disabling them from gaining more income and profit per day. Also the set of processes undertaken by the vendors during cutting of the fish is not environment friendly because they tend to throw the fish waste here and there or at the point of sale. Due to use of non-insulated crates for storage of fish, ice used melts easily and freshness of the fish is hampered. A major objective of the food processing and handling industry is to provide safe, wholesome and acceptable food to the consumer and control of freshness is essential to meet this objective (Baggen-Ravn et al., 2003). Presently, transport is one of the weak links in the supply chain and a major cause for the 30 per cent loss suffered in fish transportation. To address the problem, the National Fisheries Development Board (NFDB), Hyderabad, India has pressed into service mobile fishing vending vehicles - both four-wheelers and two-wheelers (The Hindu, 2014).

Keeping these shortcomings in mind, ICAR-Central Institute of Freshwater Aquaculture, under the aegis of ICAR-All India Coordinated Research Project on Plas- 


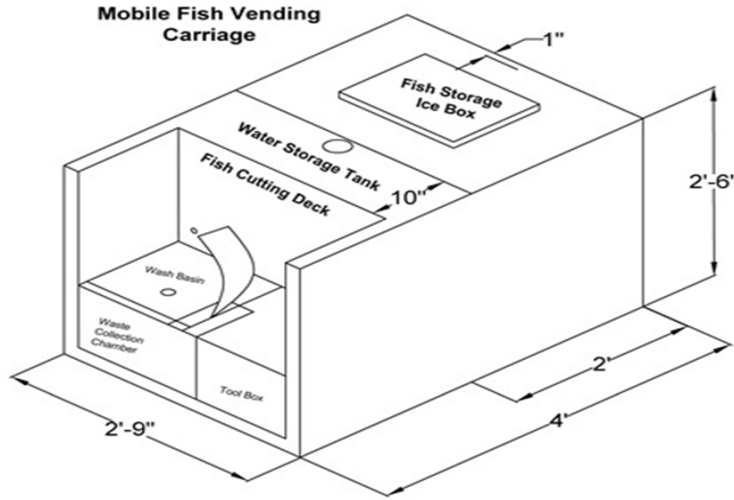

Fig. 1. Design plan of the fish vending carriage.

ticulture Engineering and Technology, has worked on designing different prototypes of a noble fish vending carriage which will be fitted on a three wheeler trolley, which can enable the fish vendors to sell more amounts of fish in the market in a single day. As per the "Guidelines for Mobile Food Vending Vehicles" of Department of Primary Industries, NSW Government, Australia (2015), a mobile food vending vehicle is any means of transport, whether self-propelled or not or otherwise designed to be movable from place to place, and which is used for selling food. Likewise, mobile fish vending trolley is a vehicle which is manually propelled with the application of pedal force by a rider and movable from place to place in order to sell fish. The prototype which seemed viable keeping in mind the economics has been designed and fabricated. Ergonomics has also been taken into consideration, so that every fish vendor can ride the total fish vending trolley easily (Sarkar et al., 2013). The ultimate motto was to aid the marginal fish vendors to improve their livelihood by selling their harvests in a large quantity per day that too ensuring proper hygienic way of fish marketing.

The objective of the work was to design and develop a noble fish vending trolley which has to be economically and ergonomically viable for the fish farming and vending community.

\section{MATERIALS AND METHODS}

ICAR-CIFA has been widely using fibre reinforced plastic (FRP) for developing different gadgets and structures for aquaculture development and promotion. These are portable FRP carp hatchery, portable FRP magur hatchery, demand fish feeder and silo fish rearing system, and these gadgets have witnessed huge success and adaptability in the farming community in India. The main reasons behind widespread use of FRP as a base material for the gadgets developed at the institute is its high strength compared to other family of plastics and ease of fabrication and maintenance (Sarkar et al., 2009). FRP is also itself a good insulator having thermal conductivity of $0.04 \mathrm{w} / \mathrm{mK}$ at normal room temperature of $25^{\circ} \mathrm{C}$ (The Engineering Toolbox, 2016). Therefore, the fish vending carriage was also fabricated using FRP as base material as per the design given in (Fig. 1).

Before designing the gadget, the weight that a normal human being can pull riding a trolley was found out as per the following calculations. (Chetan and Mahalle, 2012; Bikes at Work, 2012).

- Gross weight of the cycle rickshaw in zero load (assumed) $(\mathrm{W})=150 \mathrm{~kg}=1470 \mathrm{~N}$

- Drive used in tricycle: roller chain drive

- Gear ratio (front chain wheel/freewheel) $\left(\mathrm{r}_{2} / \mathrm{r}_{1}\right)=2$

- Length of the crank arm= $180 \mathrm{~mm}$

- Measured speed of the tricycle $\left(\mathrm{V}_{\max }\right)=2 \mathrm{~m} / \mathrm{s}$

- Desired acceleration time $\left(\mathrm{t}_{\mathrm{a}}\right)=10 \mathrm{~s}$

- Coefficient of rolling resistance between tyre and $\operatorname{road}\left(\mathrm{C}_{\mathrm{rr}}\right)=0.017$

- $\operatorname{Gradient}(\mathrm{G})=0$

- Radius of wheel $=330 \mathrm{~mm}$

A bicyclist moving in a straight line at constant speed has four sources of resistance:

- Air resistance/ Wind resistance

- Rolling resistance

- Gravity resistance/ Gradient

- Friction

Force to be applied to overcome each resistance can be calculated as below:

Wind resistance $\left(\mathrm{F}_{\mathrm{w}}\right)$ :

$\mathrm{F}_{\mathrm{w}}=1 / 2 \times \mathrm{C}_{\mathrm{d}} \times \mathrm{A} \times \rho \times \mathrm{v}^{2}$

$=1 / 2 \times 0.9 \times 0.6764 \times 1.275 \times(3.88)^{2}$

$=5.84 \mathrm{~N}$

$\mathrm{C}_{\mathrm{d}}=$ Coefficient of drag (about 0.9 for a standard

bicycle)

$\mathrm{A}=$ Frontal cross-section area of bicycle, rider and

cargo

$\rho=$ Density of air $\left(1.275 \mathrm{~kg} / \mathrm{m}^{3}\right)$

$\mathrm{v}=$ Wind speed relative to the cyclist ( Normally its 14

$\mathrm{km} / \mathrm{h}=3.88 \mathrm{~m} / \mathrm{s})$

Rolling resistance $\left(\mathrm{F}_{\mathrm{rr}}\right)$ :

$\mathrm{F}_{\mathrm{rr}}=\mathrm{C}_{\mathrm{rr}} \times \mathrm{W} \times \cos (\operatorname{atan}(\mathrm{G}))$

$=0.017 \times 1470 \times 1$

$=24.99 \mathrm{~N}$

$\mathrm{C}_{\mathrm{rr}}=$ Coefficient of rolling resistance $(0.017)$

$\mathrm{W}=$ Total weight of the rider, vehicle \& cargo

$\mathrm{G}=$ Grade/ Slope (in \%)

Gravity $\left(\mathrm{F}_{\mathrm{g}}\right)$ :

$\mathrm{F}_{\mathrm{g}}=\mathrm{W} \times \sin (\operatorname{atan}(\mathrm{G}))$

$=1470 \times 0=0 \mathrm{~N}$

$\mathrm{W}=$ Total weight of the rider, vehicle \& cargo

$\mathrm{G}=$ Grade/ Slope (in \%)

The accelerating force is also needed to be calculated:

$\mathrm{F}_{\mathrm{a}}=$ Accelerating force $=\mathrm{W} \times \mathrm{V}_{\max } / \mathrm{gt}_{\mathrm{a}}=1470 \mathrm{x}$ $2 / 9.8 \times 10=30 \mathrm{~N}$

$\mathrm{F}_{\mathrm{R}}=$ Total tractive effort $=\mathrm{F}_{\mathrm{w}}+\mathrm{F}_{\mathrm{rr}}+\mathrm{F}_{\mathrm{g}}+\mathrm{F}_{\mathrm{a}}$ (Chetan and Mahalle, 2012)

So, $F_{R}=5.84+24.99+0+30=60.83 \mathrm{~N}$ 
Table 1. Fabrication process of the Mobile fish vending Unit.

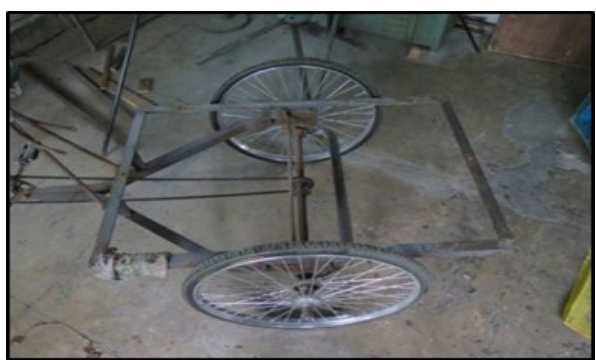

A tricycle was procured from the local market and the carriage holding frame was fabricated at the rear end of the tricycle as shown in the picture. The final fish vending carriage was installed on this frame.

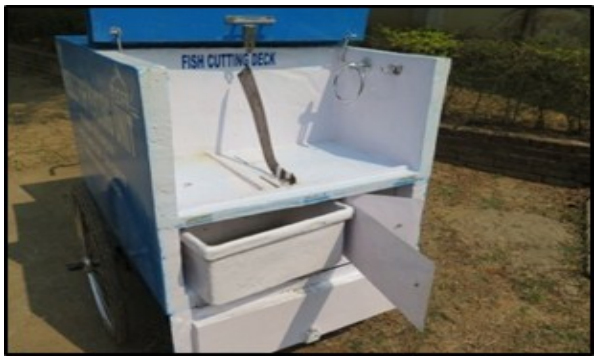

The cutting tool and other accessories were fitted on the fish cutting deck of the carriage unit and finally the unit was placed on the carriage holding frame.

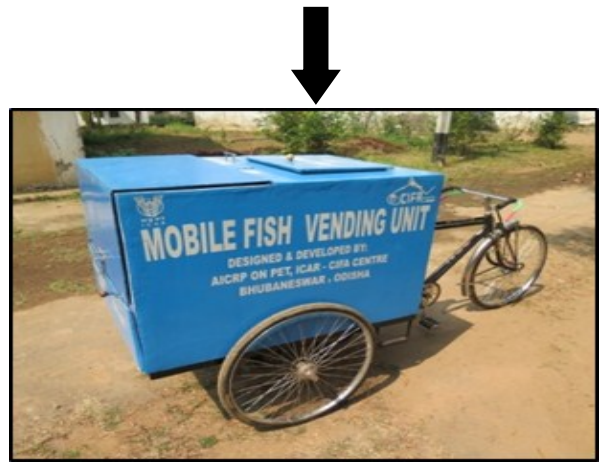

This is the final version of the fabricated Mobile Fish Vending Unit.

Friction $\left(\mathrm{F}_{\mathrm{f}}\right)$ :

It is usually considered to be $5 \%$ of the applied power on bicycle.

$\mathrm{F}_{\mathrm{f}}=0.05 \times \mathrm{F}_{\text {applied }}$

We know, $F_{R}=\left[\left(F_{\text {applied }} \times r_{c}\right) / r_{w}\right] r_{2} / r_{1}$

$60.83=\left[\left(\mathrm{F}_{\text {applied }} \times 180\right) / 330\right] \times 2$

$\mathrm{F}_{\text {applied }}=55.76 \mathrm{~N}$

So, $F_{f}=0.05 \times 55.76=\underline{2.79 \mathrm{~N}}$

Power is the product of force and velocity. So, the total power is given by:

$\mathrm{P}_{\text {applied }}\left(\mathrm{F}_{\mathrm{w}}+\mathrm{F}_{\mathrm{rr}}+\mathrm{F}_{\mathrm{g}}+\mathrm{F}_{\mathrm{a}}+\mathrm{F}_{\mathrm{f}}\right) \times \mathrm{V}$

$=(5.84+24.99+0+30+2.79) \times 2 \quad\left[\mathrm{~V}=\mathrm{V}_{\max }\right]$

$=129.24 \mathrm{Nm} / \mathrm{s}$

Therefore, the total weight that can be pulled is

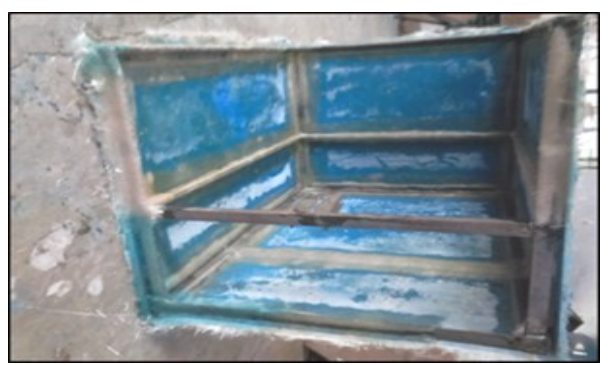

An iron frame was made using MS angles as shown in the picture to form the skeleton and holding structure of the walls of the carriage box. The dimension of the frame is $4.0^{\prime}(\mathrm{L}) \times 2{ }^{\prime} 9^{\prime \prime}(\mathrm{B}) \times 2^{\prime} 6^{\prime \prime}(\mathrm{H})$.

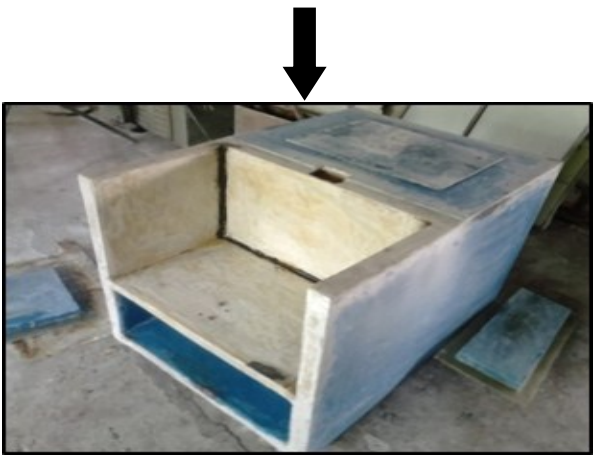

Moulds for each component were constructed and the components were fabricated using FRP in hand layup process after which these were integrated into a single carriage as shown in the picture. Electric disc grinders were used for finishing operation and paint was applied.

given by:

$W=\left(\left(0.95 \times \mathrm{P}_{\text {applied }} / \mathrm{V}\right)-\mathrm{F}_{\mathrm{w}}\right) /\left(\mathrm{C}_{\mathrm{rr}} \mathrm{x}(\cos (\operatorname{atan}(\mathrm{G}))+\right.$ $\sin (\operatorname{atan}(\mathrm{G})))$

$=((0.95 \times 129.24 / 2)-5.84) /(0.017 \times 1)$

$=3267.59 \mathrm{~N}=3267.59 / 9.8 \mathrm{~kg}=333.42 \mathrm{~kg}$

Therefore, from the above calculations it was found that a maximum $333.42 \mathrm{~kg}$ of total load (trolley load + luggage load) can be pulled by a man using the trolley, if the weight of the trolley in zero load condition is kept $150 \mathrm{~kg}$ or $1470 \mathrm{~N}$. So, while planning the design and fabrication, it was tried to keep the gross weight of the trolley and carriage box up to $150 \mathrm{~kg}$ and the ice box dimensions to carry a load of $100 \mathrm{~kg}$ fish and ice in combination.

The dimension of the whole carriage was $4.0^{\prime}$ (L) $\mathrm{x}$ 2'6" (H) x 2'9' (B), out of which half of the structure contains the insulated crate of 2.0 ' x 2'9" x 2'6" dimension for storing ice and fish. The rest of the carriage contained the water storage tank of 201 capacity, fish cutting deck with wash basin and cutting tool with working area of $0.4 \mathrm{~m}^{2}$, waste collection chamber and tool box. The fish storage box was lined with 1" thick polyurethane foam to act as the insulating material. In commercial general purpose ice boxes, 1 " thick insulated foam was used according to industry standards because urethane has more R-value per inch of 
thickness (Sizes, 2016). This was the reason why we also tried to use this thickness of insulation foam.

A tri-cycle was procured from the market and the fabrication process of the carriage started with building a skeleton structure of the boxes and trolley carrier using MS angles. Plywood moulds were constructed to fabricate the outer and inner walls of the carriage box using FRP in hand lay-up process. After that rigid polyurethane foam was lined inside the space between outer and inner walls of the ice box. Finally the whole carriage unit was placed on the trolley carrier frame and the fabrication process of the mobile fish vending unit was completed. The whole process of fabrication in step-wise is shown in (Table 1).

\section{RESULTS AND DISCUSSION}

With 9.51 million tonnes production, India is the second big fish producing country in the world after China. As per the action plan of the National Fisheries Development Board (NFDB), 250 model fish markets have been set up across the country for hygienic fish marketing. It has set an ambitious target of achieving an additional one million tonnes of fish consumption per annum in India by stepping up sales through mobile fishing vending vehicles. It has a plan to provide one lakh vehicles to fishermen and fisherwomen across the country for fast fish delivery (The Hindu, 2014).

The speciality of the fabricated mobile fish vending unit is its unibody design. Everything that is required by a general fish vendor during vending process is integrated into one single carriage box. Sarkar et al. (2013) had designed a fish vending trolley in which two separate insulated ice boxes were kept on a holding frame and assemblage of different components like fish cutting area, waste collection crate, water bucket, tool box at proper places. The resulting structure seemed not viable for high scale transportation and marketing because of limited availability of fish storage area and improper placement of a few components. So, presently it was tried to make an insulated carriage box which will look like a single ice box to the outside, but all the components are integrated into the unit. The whole carriage was made using FRP because it itself is a good insulator of heat and coupled with 1" thick Polyurethane foam so that the ice inside the ice box will not melt easily and will allow the fish to stay fresh for a longer period of time. There is a provision of a wash basin on the fish cutting deck which will be utilized for washing purposes and the waste water and waste generated during cutting of fish will be collected in a waste collection box kept inside the waste collection chamber. Due to this the fish vendor will not throw the waste here and there and this is a positive application in terms of environment and waste management practices. The tool box will be used to store the money box, cutting tools and accessories required during the fish marketing process.
The FRP mobile fish vending unit has been solely designed and developed for the benefit of the marginal fish farmers and vendors so that they can utilize this as a tool to increase their revenue generation by selling their harvests in a large quantity and most importantly in a hygienic way. This trolley will definitely be a boon for the farmers because customers are attracted to hygienic way of selling by the vendors and this unit has been developed keeping hygiene as a most important factor. Economically, this fish vending unit is also very much viable because the vendors can sell large quantities of fish in a single day and profit generation will be positively affected.

The cost of fabrication of the whole system was kept around Rs. 50,000/- which is minimal as per industry standards so that after commercialization and subsequent agricultural subsidization by the Indian government, every fish farmer and vendor can purchase the unit and improve his revenue generation and livelihood as a whole.

\section{Conclusion}

The mobile fish vending trolley was developed for the purpose of aiding the low-mid income group fish vendors enhance their daily income by selling more amounts of fish in a single day and promote hygienic methods of marketing fish. The ice box has been so fabricated that it can store fish for a longer period of time in order to enable the fish vendor to broaden his area of operation in the market.

\section{ACKNOWLEDGEMENTS}

The authors are thankful to the Indian Council of Agricultural Research for financial assistance through AICRP on Plasticulture Engineering and Technology. The authors are also thankful to the Director, ICARCentral Institute of Freshwater Aquaculture, Bhubaneswar for support and facilities provided to carry out the work.

\section{REFERENCES}

Baggen-Ravn, D., Ng, Y., Hjelm, M., Christiansen, N.J., Johansen, C. and Gram, L. (2003). The microbial ecology of processing equipment in different fish industriesanalysis of the micro flora during processing and following cleaning and disinfection. International Journal of Food Microbiology, 87: 239-250

Bikes at Work (2012). 'How Much Weight Can A Bicycle Carry'. Retrieved March, 07 2016. from http:// www.bikesatwork.com/ blog/how-much-weight-can-abicycle-carry.

Chetan, A.S. and Mahalle, A.K. (2012). Design Optimization of Speed Ratio for Conventional Chain Drive Used In Tricycle. International Journal of Innovative Technology and Exploring Engineering, 1(1): 40-43

Guidelines for Mobile Food Vending Vehicles (2015). Department of Primary Industries, NSW Government, p. 4.

Kyangwa, I. and Odongkara, K. (2005). Sanitation, Fish 
handling and Artisanal fish processing within fishing communities: Socio-cultural influences. Socio-economic Research Report-6, Lake Victoria Environmental Management Project, NARO-FIRRI, Jinja. 2 pp.

Sarkar, B., Majhi, D. and Mohapatra, B.C. (2009). Fabrication techniques of Fibre Reinforced Plastics. Application of Plastics in Aquaculture, Indian Council of Agricultural Research- Central Institute of Freshwater Aquaculture, Bhubaneswar, 19-30 pp.

Sarkar, B., Sahu, B.B., Mohapatra, B.C., Barik, N.K., Majhi, D. Jayasankar, P. and Bhatnagar, P. (2013). Design and development of an innovative mobile fish vending unit for retailers. International Journal of Innovative Technology and Exploring Engineering, 2 (3): 158-162
Sharma, C. (2010). Women Fish Vendors in India: An Information Booklet. International Collective in Support of Fishworkers (ICSF), Chennai, pp. 8-9 .

Sizes (2016), 'Typical R-values'. Retrieved March, 092016 from https://sizes.com/units/rvalue.htm

The Engineering Toolbox (2016). 'Thermal Conductivity of Materials and Gases'. Retrieved March, 092016 from $\mathrm{http} / /$ www.engineeringtoolbox.com/thermalconductivity-d_429.html

The Hindu (2014). 'NFDB plans to step up fish sales'. Retrieved March, 092016 from http://www.thehindu.com/ news/cities/Hyderabad/nfdb-plans-to-step-up-fish-sales/ article6558096.ece. 